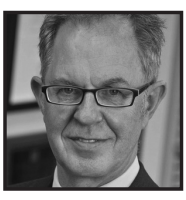

\title{
Push, Pull and Nudge: The Future of Teaching and Educational Change
}

\author{
Andy Hargreaves
}

From "Push, Pull and Nudge: The Future of Teaching and Educational Change," by Andy Hargreaves, 2011. In X. Zhu and K. Zeichner (eds.), Preparing Teachers for the 21st Century, New Frontiers of Educational Research, DOI 10.1007/978-3-642-36970-4_13, pp. 217-236. Copyright @ Springer-Verlag Berlin Heidelberg 2013. Reprinted with permission.

\section{ABSTRACT}

This paper draws on recent research on teacher collegiality and professional learning communities to unpack the nature, benefits and drawbacks of different forms of collegial relations, especially in circumstances of high stakes reform. In particular the paper examines the relative merits of pulling change by inspiring and enthusing teachers in their efforts by appeal to the moral principles of their work, or pushing change by placing teachers in situations requiring changes in practice in the hope that this will then lead to changes in their beliefs. The paper finds that teachers sometimes have to be drawn or pulled into professional learning communities, and sometimes they have to be driven or pushed by them. However, pulling should not be so weak that it permits no collaboration at all, and pushing should not be so excessive that it amounts to shoving or bullying. Instead, collaboration will often require the nudges of deliberate arrangements to enhance learning.

\section{Introduction}

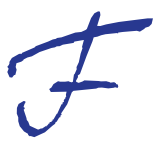

or thousands of years, teaching was a practice conducted by individuals in relation to other individuals or entire multitudes. Buddha, Mohammed, Moses and Jesus; Confucius in the East, and Socrates in the West 
- all these founders of great spiritual, philosophical and cultural traditions were iconic and charismatic teachers - they purveyed wisdom, conveyed knowledge and sometimes inveighed against social convention and intellectual complacency. They told inspiring stories, posed probing questions, and presented life insights through conundrums and riddles - challenging those who wanted to learn from them at every step. They were teachers who had teachings, and the teachings were supposed to be followed, even if that entailed finding a path for oneself.

If teachers and those who judge them regard the work of teaching as being an essentially hierarchical and individual act - in historical, philosophical and even spiritual terms - they have therefore come by it honestly. They are part of a respectable and revered tradition that stretches back more than two Millennia.

Challenges to the traditional and, many have thought, unavoidably hierarchical nature of the teacher-pupil relationship (Waller 1932), have been prominent during particular historical periods. These include the Progressive Movements of the 1920s and 1930s following World War I in the US, UK, Germany and other parts of Europe; the economically expansionist and culturally questioning era of the 1960s and early 1970s in both the West and parts of Asia; and now, once more, a turn away from teaching to learning, and standardized instruction to personalized learning in the internet age of independent online access and participation in social media in the twenty-first century.

More recent than the historically repeated attempts to transform teaching from hierarchical transmission to facilitation, from authority to authenticity, and from classroom hierarchy to democracy, has been a systematic and sustained assault on the culture and even the cult of teacher individualism. This assault has challenged the second deep-seated idea that teaching is an act performed alone, as an individual, in isolation from all other teachers in the vicinity (Little 1990; Rosenholtz 1991).

If professional collaboration in talking about teaching, planning teaching and performing teaching together was at first an ideal or even an ideology, over the past 20 years, there has been an accumulating body of evidence that professional collaboration which is related to student learning, produces better learning outcomes, improves teacher retention and brings about more successful implementation of change, than teaching which is conducted mainly in isolation from other teachers (Hargreaves 1994; Newmann and Wehlage 1995).

This has led to widespread efforts to design and even dictate specific architectures of collaboration in the form of what are called professional learning communities 
which redefine expectations for the work of teaching and the profession of teaching in order to improve learning outcomes for students and to implement change successfully within the system (Hord 1997; McLaughlin and Talbert 2001). In many countries, the institution of professional learning communities is redefining the form and the future of teaching as a job that is performed, or at least planned and reviewed collectively and transparently, so there is little left in teaching and learning that is private. Key data about pupil behaviour and performance are increasingly accessible to and analyzed by professional colleagues in real time to trigger just-in-time interventions for students and also to manage and monitor implementation of reform.

This paper analyzes the nature and dynamics of professional collaboration in an age of increasingly data-driven, large-scale, standards-based reform - where improved learning outcomes for students and incessant attention to reform implementation sit in an uneasy relationship beside one another and are each subsumed by the same technology of professional learning communities. In order to do this, the paper revisits and revises a concept I created two decades ago - contrived collegiality - and then investigates how this concept or the process it refers to plays out within the modern context of professional learning communities. It argues against securing increased professional collaboration through strategies of administrative force on the one hand, or voluntaristic freedom of choice on the other. Against these extremes, it counterposes, but also critiques, a strategy of developing professional collaboration or professional learning communities, through a combination of pushing, pulling and nudging professional peers in the direction of desired change that benefits students without undermining teachers' professionalism. In making the argument, the paper draws on recent investigations I have conducted with various colleagues on professional collaboration in high performing educational systems across the world in Europe, North America and Asia as well as organizations in other sectors (Hargreaves and Braun 2012; Hargreaves and Shirley 2012; Hargreaves and Fullan 2012).

\section{Arranged Collegiality}

Some years ago, I was invited to dinner with a group of principals in Australia. Midway through the main course, one of the principals said, "Do you mind if I ask some advice?" He described problems he was having with a teacher who refused to collaborate, even though, paradoxically, the dissertation the teacher had recently completed for his graduate degree was on professional collaboration. When asked to give some examples, the principal said: 
"Well, at the start of staff meetings, we usually begin with an ice-breaking activity, and he refuses to do it".

Back came the probing question. "How long have you been at your school?" "What are the relationships among the other teachers like?"

"Actually, they're very good. I've been there a few years and we have worked a lot together. The trust levels are really high".

"So perhaps there's no ice to break, then!" came my reply.

"That's funny", the principal said. "You may be right. He keeps accusing me of this thing... What does he call it? Contrived collegiality!"

"I have bad news for you"I responded. "I invented the term!"

It is one thing to value professional collaboration as an ideal. It is another to be able to develop and enact a theory of change that will bring desired levels and forms of collaboration into being. Should teachers be encouraged to collaborate then be left alone to do it themselves? Or, if the benefits are so great for students, should they be forced to collaborate, even if it does not suit their own professional needs and styles as adults?

In educational change, it is sometimes said that human beings, like physical objects, usually prefer to be at rest: to remain just where they are. In line with the laws of physics, some kind of force will therefore be required to move them. What kind of force should it be, and who should exert it? Should teachers be pushed, pulled, dragged, drawn or lifted? Is a great shove needed to move them forward and keep doing so, or will just a small nudge be enough to get them moving by their own momentum?

Collaboration is a particularly challenging goal for change efforts. Cultures of professional collaboration don't evolve quickly. They depend on the proof of repeated interactions that establish a foundation of respect and trust (Nias 1989; Datnow and Park 2012; Finnigan et al. in press). The time required to build authentic collaborative relationships to which people make willing commitments can be unattractive to administrators who seek swift solutions or are driven by their systems to produce shortterm results.

Not only do collaborative cultures take time, but they can also be unpredictable in their consequences. The curriculum that will be developed, the learning that will be fostered, the innovations that will be created, cannot be planned or predicted exactly in advance. For some administrators, this unpredictability can be disconcerting. What is developed by these collaborative cultures may not always correspond to administrators' own preferences or current reform priorities. Just as votes in an election can go against you, so can collaborative cultures. So administrators often prefer forms 
of collegiality that they feel they can control - meetings with a predetermined agenda, working groups you can list on paper, or data teams that produce specific results. These more regulated kinds of collaboration are what I have termed contrived collegiality (Hargreaves 1994).

Contrived collegiality is characterized by formal, specific bureaucratic procedures to increase the attention being given to joint teacher planning and other forms of working together. It can be seen in initiatives like peer coaching, mentoring schemes, data-driven team meetings and inquiry projects. These administrative contrivances can get collegiality going in schools where little or none existed before. They are meant to encourage greater association among teachers and to foster more sharing, learning and improvement of skills and expertise. They are a way to nudge new kinds of interactions and relationships into existence.

In their widely used book Nudge: improving decisions about health, wealth and happiness, Richard Thaler and Cass Sunstein (2008) argue against two flawed theories of change that underpin many administrative and policy efforts to alter behaviour. Except where it is absolutely necessary and the protection of public safety is at risk, they argue, attempts to alter behaviour by the first strategy of compulsion or force usually backfire in generating resistance to and avoidance of change. We have seen this, for example, in models of policy delivery where standardized tests or other key performance indicators are linked to high-stakes system targets for improvement with punitive consequences for those who fall short. In education, health, policing and even management of railways, high speed pressure for measurable improvement provides employees with "perverse incentives" to teach to the test or concentrate undue attention on pupils very close to the passing mark in education, to redefine certain crimes as misdemeanours in policing in order to give the appearance of improved crime rates, to reduce or eliminate safety checks in order to meet the schedules of railway construction or repair, and to drive dangerously ill patients in an ambulance round and round their hospital until the emergency room waiting time within the hospital will be short enough to meet the government target (Bird et al. 2005). Force drives people to game the system and produce the appearance of compliance, even and including when force is applied to requirements for professional collaboration.

The opposite of overwhelming force is unlimited choice. This too, say the authors of Nudge, is a detrimental option. In The Paradox of Choice, Barry Schwartz (2005) argues and shows that too much choice can be bad for us. It makes us confused, frustrated and unhappy, because out of all the options available, we can never be truly sure we have made the right or completely the best choice - be this shoes for our feet or 
schools for our children. More than this, say Thaler and Sunstein, when consumers are overwhelmed, they will often make choices, or fail to make choices in ways that are bad for them - especially when the results of those choices are long term and can easily be overshadowed by other choices that yield short-term rewards. This, they say, is why people often choose to purchase and consume foods that are bad for their health, or why they fail to review their pension fund investments to safeguard their long term retirement.

What the authors of Nudge argue for instead of inescapable force and unlimited choice is ways to "nudge" or prod people's choices in one direction rather than another, reducing the range of choice and increasing the probability that people will then choose the behaviours that are in the best interests of themselves or those they serve. Some of these nudges are normative: they are in the language we use and the expectations we set. Others are structural: they are arrangements of the organizational or physical environment to make some choices more likely than others. Placing fruit rather than sweets or candy bars next to the supermarket checkout, shifts the likelihood of what people will buy, on impulse, as they line up to pay. Making the best rather than worst pension option the default option for those who don't actively choose, again instigates a structure that channels people's own choices into more beneficial areas, rather than harmful ones. Nudging, say Thaler and Sunstein, isn't meant to be a way to deceive consumers, or hoodwink people into harming themselves. It is a way to deliberately organize and arrange the structures and norms of organizations to increase personal benefit and public good.

When nudging is applied to cultivating collaborative behaviour, this is one way in which we might use the term, contrived collegiality, though in this benign sense, after Norwegian scholar Kirsti Klette (1997), I prefer to call it arranged collegiality. Arranged collegiality is a way of putting teachers in contact with each other. Principals and peers can then build on resulting elements of recognition, trust and support to focus conversations and activity more tightly around teaching and learning.

Arranged collegiality is evident in shrewd scheduling that releases the right people to have an opportunity to plan together, within a grade level or across departments, perhaps. Principals can use their own time to cover classes and facilitate this planning. Putting the new teacher and an experienced and accomplished colleague in adjacent classrooms is another way to nudge forward a process of informal mentoring. Arrangements and expectations can be established for special education teachers to meet with regular classroom teachers and work with them in their own classrooms. Protocols can be written where teachers can examine students' work in their respective 
classes. These kinds of arrangements make it more likely (though not certain) that hightrust collaborative cultures will develop.

What people believe and how people behave (the substance of a culture) is, in other words, profoundly affected by their connections to and subsequent relationships with who does or doesn't believe it (the form of a culture). Change the form of a culture (the interactions among people) through the medium of arranged collegiality and you have a good chance of changing its content too (Hargreaves 1994). Take the case of special education in Ontario, Canada.

Barry Finlay was a quarterback in university and went on to play five years in the Canadian Football League (CFL). A quarterback must see the relationships among all the players on the field. He's the systems thinker of football. Towards the end of his athletic career, Barry started getting involved in coaching young men who others had found challenging in terms of their discipline or behavior. He enjoyed working with them, empathized with them and felt he made a difference to these youngsters who hadn't really fit in anywhere else. Barry was now a systems thinker with a moral purpose and a mission.

Barry's teaching experience led him into special education - with kids on the margins who needed some learning support and guidance in their life. Moving on to take his Masters degree in Educational Administration, he focused on organizational learning and on how everything was connected to everything else in the big picture of change. As a principal of a new innovative high school, Barry then became a systems thinker in action. He organized teaching in Grades 9 and 10 so that students were shared mainly among four teachers, who taught as teams, knew what each other was doing and grasped where all the program was. When substitute teachers came in, for example, they weren't just babysitters, but they slotted right in to the whole team. They were now big picture thinkers too. They all understood how the school worked and what their own contribution was. His effective use of arranged collegiality enabled everyone to see and be responsible for the big picture of school change.

Eventually, Barry became Director of Special Education for the whole of his province. Here was his chance to apply his systems thinking to his passion for special education and for supporting all learners. One of his first moves, against some opposition, was to move his office from a separate building, marginalized from the Ministry offices, into the main building itself. If he was outside the mainstream, he reasoned, how could he persuade districts and schools to make special education part of the mainstream themselves? He realized that if he wanted to change people's beliefs about special education, he had to change the relationships and interactions between special education and other personnel - and he realized this had to start right at the top, with himself and his colleagues.

Barry knew how children with special educational needs had often been separated out from other children - "withdrawn" from classes, taught in separate units or distant portable classrooms far away from the rest of the school. Barry presided over a new provincial philosophy that believed that what was essential for some children was good for all of them - that if you wanted to help children with special educational needs, you had to transform the whole school. Special education teachers worked in teams and in classrooms with regular classroom teachers. They developed senses of shared responsibility for the same 
children and their progress. Special education teachers started to help all children who found parts of their learning difficult; not just the ones who had been formally identified as having special educational needs. And in school district offices, special education and curriculum departments began to work more closely together - sometimes becoming almost indistinguishable from each other. All this helped promote the philosophy and practices across the system where whole-school changes like providing differentiated instruction or offering assistive or enhancing technologies for all students, particularly benefited those who had identified disabilities.

Barry Finlay grasped that if you want to change people's practices and beliefs, you have to alter or arrange patterns of communication and build new kinds of relationships among them. This may involve changing people's roles or changing the structures of an organization - but the goal is to reculture schools, districts and whole systems so they serve all their children better.

Arranged collegiality can therefore instigate new cultures and relationships of a more collaborative kind, through establishing common norms, creating a common language and placing people in closer proximity to each other in order to develop senses of shared responsibility. At the same time, arranged collegiality can also disturb collective complacency or groupthink and extend what teachers collaborate about.

\section{Contrived Collegiality}

By looking at achievement data, examining learning profiles of particular students, or comparing how different teachers might assess examples of students' assignments, arranged collegiality can also sharpen the focus of joint work among teachers (Datnow 2011). However, there is a fine line between arranged collegiality and contrived collegiality.

Cultures of professional collaboration take much more time, care and sensitivity than speedily implemented changes or hurriedly assembled teams allow. Arranged collegiality can prod and nudge this process forward by creating opportunities, incentives and also expectations for teachers to work together, but there are still no quick fixes. Arranged collegiality, however, certainly does not mandate collegial support and partnership through fear and force. When arranged collegiality turns into more questionable contrived collegiality, colleagueship and partnership are administratively imposed, creating a degree of inflexibility that violates the discretionary judgment that 
is central to teacher professionalism. Let's consider two such examples of imposed or contrived collegiality:

\section{Coaching}

The first comes from research on peer coaching by a former graduate student, Jane Skelton (Hargreaves and Skelton 2011). Peer coaching relationships where one teacher assists one or more fellow teachers to improve their teaching or learn a new skill can take many different forms - some more empowering than others. Some of these don't just encourage teachers to work together on improvements they identify, but mandate that they work together to implement prescribed programs with fidelity.

Here is a US literacy coach and some teachers discussing their struggles in using mandated common planning time so that special education teachers could respond to short vignettes about their work with a prescribed vocabulary curriculum. The coach's job is to steer an agenda related to the district's goals within a mandated common planning period, but where there is shortage of time more generally.

Coach: I I struggle with having to get the conversation going. Sometimes I feel like I say a lot. I do a lot of "okay." Time is always the constraint. It's always the big factor. I've always struggled with what are the questions you have to bring forth in the moment to get things going. You don't want to say too much. You don't want to say too little.

Teacher 2: There's a point where if you try to do so much you don't get anything done. I understand the time constraints, but l'd rather come out with a little bit of information that I really know and I can really use. I'm more into the concrete.

Coach: Getting other folks to talk - that's my struggle. I feel pressures to have other folks speak. So I feel like I say too much up front. [I'm] just trying to get other folks to speak. (Almost all of the teachers nodded in agreement.)

Time is not the only problem here. Teachers have to deal with many other initiatives and everyday demands such as "kids coming down the hallway" or parents waiting for attention, as well as the literacy requirements, and because of budget cuts, they are not even sure they will be keeping their jobs or where they will be working the following year. 
Teacher 7: When we come in here, we have to switch off from that other stuff. We know it's Word Generation, and [we have to] focus on what we're doing.

Teacher 1: We have so many team meetings. We're at the service of the parents and if the parents come, it's just a matter of us being in two places at once.

Teacher 4: You have common planning time, you have cluster time, and there's no real sacredness to it. So everything comes before it, and you're flying by the seat of your pants. And, you sit down for a couple of minutes and you want to participate and you find yourself, like everybody else, waiting for the kids to be coming back from gym. So you can never really be relaxed.

Teacher 3: And then with this year and everyone trying to figure out their job, our minds are in different places.

Teacher 4: Finding work.

Teacher 2: The [writing prompts] still have to be corrected.

Coach: About coming from one place to the next - [the common planning time] tends to be very coach-driven. I think that there are places where I try to invite, but I think that folks feel overloaded with what they are trying to do outside of these meetings. I know that we had talked about questions (related to the vocabulary issues) and a couple of folks had brought them back. You get caught up in things. And so when you think about doing that collaborative piece.... mean, they had a parent show up this morning. They had an [individual education plan] meeting this morning. And I feel lots of times, it's like, "Can you handle this so we can deal with the parent and go to the [individual education plan] meeting? And kind of bring it back together for us week by week so that we can remain focused. (The teachers were silent.)

Teacher 2: I think that it's hard to get a format that would fit every meeting like this - professional development meetings, curriculum-based meeting[s]. Personalities have a huge part of it. No matter what you have in front of you, like - "This is the manual for it, and we're going to follow this". Forget it. It's not going to happen, because people are different. [They] react to each other differently. They react to the coach differently and vice versa.

Coaching in the context of mandated reform can often fall short of its ideals, therefore, leading to hurried, anxious and one-sided interactions, in required time periods that draw teachers away from compelling classroom concerns in a system where even basic job security can no longer be counted on. This is what, some years ago, I described in terms of "coaching as unreflective practice" (Hargreaves and Dawe 1990). Passive resistance results in the form of withholding full attention or not responding to the coach's requests to complete a survey on what students are learning. 
It is easy to argue that teachers are just dragging their feet in acquiring new and much needed technical skills. But in this case, they are actually digging in their heels to assert a contrary will that opposes the enforced transportation of unwanted programs and practices into their classrooms, especially at a time when their very jobs are up in the air.

\section{Peer Pressure}

Peer pressure of certain kinds can be a highly valuable ingredient of positive professional collaboration - when peers who are knowledgeable about your practice, and share your instructional goals, help you and even push you to be the best you can be through processes of what are called cognitive coaching and challenge coaching that provide feedback that will deepen reflection, provoke inquiry and question existing assumptions. Writers such as Michael Fullan have argued that shifting the pressure exerted by those at the top, to pressure exerted by peers - what he calls positive peer pressure - is one of the most significant transformative changes that can occur in educational change (Fullan 2011). Yet this perhaps misrepresents the change question as being one of who controls change, rather than how change is controlled. A literacy coach, we have seen, can be just as pushy as a principal. Whether it is leaders or teachers who exert pressure to collaborate is not the point. The more important argument is what that pressure looks like and whether it amounts to a nudge or a shove. Nudging is an act of collegial encouragement. Shoving can border on professional abuse.

Sometimes, peer coaching can be just another technical way to implement an external mandate - with peer coaches or system literacy coaches now acting as messengers of compliance with enforced external reforms. An interesting example of this kind of peer-mediated accountability comes from an example of peer-driven change in Ontario, Canada, described by McKinsey \& Co. To quote directly:

This is the story of a teacher who joined a primary school that had established the routines of collaborative practice as part of its literacy and numeracy strategy - these were professional learning communities through which teachers jointly reviewed student work and developed teaching methods. In that teacher's first week in the new school two of his colleagues visited him and suggested that he should use word walls because they had both found them to be effective. When, two weeks later, he had not yet put up the word walls, his colleagues visited him again, this time urging him more strongly to put up the word walls, sitting him down to share why this was the practice in their school and the difference it had made for students. A few weeks later, by then well into the school term, he had still not put up the word walls. His colleagues stopped by again after school, this time simply saying: "we are here to put up your word walls and we can help you to plan how to use them". As professionals in that school, they had developed a model of instruction that 
they found effective....so they expected others to use it too. Their commitment was to all students and to their professional norms - not just to their own students in their own classrooms - and they were willing to hold each other accountable for practices that they found effective. (Mourshed et al. 2010)

What are we to make of this example? We hear the triumphant account from the peers who pushed their incoming colleague, but there are no words as to how this process was experienced by the colleague in question, or whether he became a better teacher as a result. It's a somewhat self-congratulatory account by the pushers, not the pushed. We don't know how well these peers know, understand and have got to grips with the details of their colleague's practice, but we do hear about infrequent visits and contacts - "two weeks later" and "a few weeks later" - suggesting that these may have had some of the features of drive-by observations that are all too common in many coaching, supervision and evaluation situations. Then there is the question of whether these educators see themselves truly as professional peers at all if they can take it upon themselves to be "sitting him down". This is more of a shove than a nudge and is very different from teachers and leaders in high performing Finland, for example, who work together as peers in a "society of experts" (Hargreaves et al. 2008). And we don't hear about the approaches to literacy that this teacher already uses, whether they are effective or not, and how rich or not they might be. All we know is whether or not the teacher has a word wall - an easily observable item, torn out of context, that can be quickly ticked off a checklist by transient and micromanaging peers armed with clipboards in their quest for compliance.

Of course, it's perfectly possible that these peers did have deep understandings of and engagements with their colleague's practice and that the use of a word wall was just one well articulated part of all this. But we hear none of this. In this case, as in too many cases, it simply seems to come down to whether or not the teacher has a word wall: an example of contrived collegiality at its pushiest, most superficial and groupthink-like extreme. And in the way the example is presented by McKinsey \& Co, it uses the admirable principle of positive pressure to issue a license to exert any kind of pressure that the pushers decide on.

Some critics of the concept of contrived collegiality (which they often misread and misrepresent as contrived congeniality) wrongly claim that it is being used as a verbal weapon to defend teachers' right to teach any way they like (to shore up their individual classroom autonomy, that is) (Dufour 2011). As the arguments above make very clear, nothing could be further from the truth. But the principle that collegiality usually has to be organized, expected and arranged - often (but not always) by administrators 
- should not be used to justify and to fail to challenge the excesses and abuses of contrivance where professional collaboration is on external agendas, that other people decide, at times of their choosing, in relation to purposes in which teachers have no control and that - in the case of gaming the system to cross test score thresholds, for example - may even be suspect.

To contrive something is to do more than merely organize and arrange it. Deliberate change requires deliberate measures. But to make things contrived is to push them quite a bit further. It is to make them unnatural, false, artificial, even forced. Contrived collegiality is collaboration on steroids. In the end, the drawbacks and benefits of arranged collegiality (at its best) and contrived collegiality (at its worst) are not to be found in whether or not particular structures or practices are suddenly introduced - like planning times, protocols or procedures for analyzing data. The differences between merely arranged and artificially contrived or forced collegiality are to be found in whether there is already enough trust, respect and understanding in a culture, for any new structures or arrangements to have the capacity to move that culture ahead.

This is not a question of whether administrators or teachers should be the driving force behind professional collaboration. The question is that if there is any pressure, whether it is exerted by principals or by peers, what distinguishes good pressure from bad pressure? Pressure from peers is inherently no better than pressure from principals or other administrative leaders if the pressure is of the wrong kind, exerted in the wrong way.

These issues have been addressed by Amanda Datnow (2011) in a study of the dynamics of data-driven teams in two school districts. Using the concepts of collaborative cultures and contrived collegiality as a touchstone for her team's analysis, she found that while the collaboration promoted by both districts was administratively regulated and designed to meet the districts' purposes through such devices as mandated meeting times and prescribed questions within meeting protocols, many of the negative effects normally associated with contrived collegiality did not take hold. Rather, "what began as contrived meetings to discuss data evolved into spaces for more genuine collaborative activity wherein teachers challenged each other, raised questions, and shared ideas for teaching" (Datnow 2011).

The explanation for this finding is interesting. There was already quality, integrity and long-term stability in these districts' leadership, even before the introduction of data-driven improvement. The districts had pursued continuous improvement for 
some time and been able to "develop trust among teachers, assuage their concerns about how the data reflected upon them as individual teachers, and promote a positive orientation towards data use." (Datnow 2011). Strong collaborative cultures were the foundation underpinning the immediate efforts at data-driven contrived collegiality.

\section{Professional Learning Communities}

When it is used in a facilitative and nudging, not controlling or shoving kind of way, contrived (or arranged) collegiality can also provide a starting point, and a necessary first step toward building collaborative cultures with focus and depth - as in the case of Barry Finlay and the goals of Ontario's special education initiative to increase collective responsibility among special education staff and those with more general curriculum responsibilities. One of the most significant, sustained and systemically broad efforts to do that has taken the form of professional learning communities: a place where the pushes and pulls and nudges of different kinds of collegiality come through with real intensity.

What have we learned so far about the power of professional collaboration that can help us address the dynamics of professional learning communities? Two basic lessons stand out. First, a lot of the work of building professional collaboration is informal. It is about developing trust and relationships and it takes time. But if all this is left entirely to voluntary and open-ended choice, a lot of collaborative effort will dissipate and provide no benefit to anyone, or never even occur at all. Second, positive collaborative work can benefit from teachers sometimes being nudged forward through deliberate arrangements of meetings, teams, structures and protocols. But if these are hurried, imposed or forced, or if they are used in the absence of commitments to building better relationships, then they too will be ineffective. The necessity of arranged collegiality is no excuse for the forceful and even bullying imposition of contrived collegiality whether this is by formal superiors or by people who are technically one's peers.

Strong and positive collaboration is not about whether everyone has a word wall, or a set of posted standards, or not. It's about whether teachers are committed to, inquisitive about and increasingly knowledgeable and well-informed about becoming better practitioners together, using and deeply understanding all the technologies and strategies that can help them with this - whether it is a word wall here and there, or something else instead. The place where all these scenarios play out these days is in professional learning communities. 
Since the origins of the terms professional community, learning community, and professional learning community in the 1990s, professional learning communities have spread like wildfire. Sometimes, in line with their origins and original intentions, they have been a means to develop teachers' overall capacity for inquiry, improvement and change. Sometimes they have been used as a strategy to implement external reforms especially in tested literacy and mathematics.

Originally, the inventor of the term professional learning community, Shirley Hord (1997), simply meant that a PLC, as it later came to be called, would be a place where teachers inquired together into how to improve their practice in areas of importance to them, and then implemented what they learned to make it happen. In the spirit of this simple starting point, PLCs can be represented as comprising three things (Hargreaves and Fullan 2012). They are:

1. Communities: they are places where people work in continuing groups and relationships (not merely transient teams), where they are committed to and have collective responsibility for a common educational purpose, where they are committed to improving their practice in relation to that purpose, and where they are committed to respecting and caring for each others' lives and dignity as professionals and as people.

2. Learning communities: in which improvement is driven by the commitment to improving students' learning, wellbeing and achievement; in which the process of improvement is heavily informed by professional learning and inquiry into students' learning and into effective principles of teaching and learning in general; and in which any problems are addressed through organizational learning where everyone in the organization learns their way out of problems instead of jumping for off-theshelf, quick-fix solutions.

3. Professional learning communities: where collaborative improvements and decisions are informed by but not dependent on scientific and statistical evidence, where they are guided by experienced collective judgment, and where they are pushed forward by grown-up, challenging conversations about effective and ineffective practice.

Sadly, however, professional learning communities have often been imposed in a simplistic and heavy-handed way by overzealous administrations and workshop consultants. Too often, they have become yet one more 'program to be implemented' rather than a process to be developed. One clear example comes from Alberta in Canada. In a research team that one of us led to review the province's groundbreaking school 
improvement initiative, Brent Davis and Dennis Sumara (2009) undertook an in-depth study of three contrasting school districts and how they each approached schoolbased innovation within the province's wider initiative. One of them decided what their schools' innovations would be - professional learning communities - and imposed them on everyone. Leadership money was spent on moving one or two teachers from the schools to be coordinators in the district office (in another district, by contrast, the money was spent on providing bits of time for lots of teachers to interact and inquire into their practice together within and across their schools); and on bringing in wellknown external trainers to do multi-day workshops with school teams. The aim was to achieve alignment in the district. But in practice, the only time the schools met each other was during the workshops. Because leadership was concentrated in the district office and imposed from the top, none of the schools knew what the others were doing. Ironically, the district ended up getting very little alignment at all because the PLCs were laid on, there was not enough leadership to spread around, and the only learning that was going on was from the external consultants.

Diane Woods' (2007) research pinpoints how PLCs, like many reforms, are often viewed differently by people at the top compared to those on the ground. Charles Naylor (2005), a professional development leader for the British Columbia Teachers' Federation, has seen how the importation and implementation of Professional Learning Communities from the United States has fared in high capacity, high performing Canada and is not impressed with the results. The worst proponents of PLCs, he says, avoid connecting them to innovative and ambitious learning goals but stick to the technicalities of specifying narrow performance goals, defining a focus, examining data and establishing teams.

There is a dilemma here. If someone doesn't push PLCs, there is a worry that individually autonomous teachers may not get around to purposeful interaction. But a push can quickly convert a nudge into a shove. More than this, do we really want improvement to happen as a result of a collection of change pushers? Why does change always have to be driven or pushed from somewhere else or by someone else? Change isn't a drug. It shouldn't turn agents into pushers. In a study I have conducted with Alma Harris on organizations that perform above expectations in business, sport and education, one of the organizations is a highly successful craft brewery, featured on the Discovery Channel - Dogfish Head beer - that has unusual and innovative ways of approaching change and improvement. The case study writers here were Corrie Johnson and Alex Gurn. 
At Dogfish Head Craft Brewery, the Dogfish way of creating "off-centered ales for offcentered people" is all about living life counter-intuitively, against the grain. Dogfish Head's employment of 'opposite- approach strategies' works to turn conventional industry practice on its head and circumvent the big three US beer companies' attempts at structured market domination. For instance, instead of adopting conventional push strategies of marketing, which advertise the product far and wide, Dogfish Head uses pull-marketing at craft beer events and the like that devote time face to face with people and that develop a cult following. "From the outset, it's still this fun, funky thing that people just gravitate to", they say. (Hargreaves and Harris 2011)

It sounds like tough talk - the kind that appeals to politicians and high level administrators in places like the US - to be saying we need to be pushing things all the time, either from above or from one's peers. But professional learning communities, collaboration, and change in general, are as much about pulling people towards interesting change by the excitement of the process, the inspirational feeling of the engagement, the connection to people's passions and purposes, the provision of time that is not consumed by classroom responsibilities or mandated change agendas, and the creation of not just a spreadsheet of higher test scores, but a culture of engaged and successful learners. Create positive energy and excitement in relation to a commonly valued goal and you will always pull lots of people towards you. Here is an example from Limeside Primary School in the North of England - part of the Beyond Expectations study conducted with Alma Harris. Kathryn Ghent was the fieldworker at this school.

In June 2000, Limeside Primary School, on a deprived council estate in the North of England, was classified by the English inspection service, OfSted, as needing to go into "Special Measures". Less than a third of the children were reaching proficiency on standardized achievement tests and many children were leaving school "not able to read". "It really hurt", the headteacher recalled. The school was "a slum school that nobody wanted to go to, in a slum estate that nobody wanted to live in". "There were no real expectations for the children. It was kind of, 'Well they're Limeside children, so what can you expect?'"

Over the years, the school turned around with many familiar strategies such as establishing a calm climate with a positive behavior strategy, setting a common vision, relentlessly tracking children's progress, and changing teachers' roles and responsibilities. The great leap forward, though, was higher expectations for success from everyone and the teaching and learning strategies to match them. These days, in the words of a teaching assistant, "Limeside gives them the confidence to achieve".

The strategies were collective and often counterintuitive to the relentless, earnest push to track and drill people to get improvements in measurable results. Teachers were pulled as much as pushed forward by energizing innovations that yielded increased engagement as well as achievement. Philosophy sessions enabled children to discuss school rules and problems in an open forum. The headteacher introduced meditation each morning to settle children and staff into the day. Children are also explicitly taught prior learning, learning styles and meta-cognition. Wall displays show jigsaw puzzle pieces with the key 
thinking skills and activities within them. Children are able to follow the framework, looking at prior knowledge, identifying the task, working together and trying to find the best way of solving the problems, then teaching somebody else when they've managed it.

The school bought wizard hats and cloaks and anybody who has shown they are a wizard learner in mastering the key thinking skills is dressed up in assembly to receive their certificate. "The wizard learner is a real event and this wizard is able to ask questions. He's able to work with somebody else. He's able to do lots of home learning. He's able to know what to do when you don't know what to do." The consequence is confidence, accomplishment and more collective confidence for children and teachers alike. "It's a major high when you see a child that has struggled and struggled but persevered and has shown that 'I am going to do this' and they walk up on that stage at the end of so many weeks and they get there and what they say is, 'I've turned a corner, I can do it and not only can I do it but I can show somebody else how to do it.' That's a real high when you see that".

In general, we need to move the debate away from pushing PLCs per se into developing processes where teachers will encourage and challenge each other as well as challenge their leaders as part and parcel of the give and take of continuous improvement. Again, there needn't be an ideological battle between tender words and tough talk, between pushing and pulling as well as nudging change forward. Usually, what will be involved from different quarters is a bit of push, a bit of pull and a bit of push back. And when all the forces come together, the results can be dynamic. All this is evident in an Ontario school district that has been studied as part of an investigation co-directed with Henry Braun of special education reform strategies in 10 (of the 72) districts in the province (Hargreaves and Braun 2012). Here is an example from one of the districts where the push and pull of administrative superiors in developing and administering professional learning communities becomes a push too far for some colleagues. This is an edited and extended report from the original account of case writer, Matt Welch.

Dave Perkins (a pseudonym and composite of two district administrators) is Director (superintendent) of a Northern Canadian school district that has 24 elementary and secondary schools with a $40 \%$ population of First Nations (aboriginal) students in a far-flung territory the size of France.

We investigated how Dave's district used project funding for whole-school approaches to special education reform. Every district took a different approach. Dave's district initially used its resources for supply (or substitute) teacher coverage to allow both general and special education teachers to attend PLC meetings together and for "capacity building" more generally. The reflective aspects of PLCs in this district allowed teachers to increase their awareness that the significant language challenges of their aboriginal students were less a matter of inherent and insurmountable cognitive impairment, but a developmental and experiential issue that could be addressed collaboratively as well as pedagogically.

Dave and his colleagues pulled teachers in by having flexible formats and focal points in different schools and by funding ample release time to break down the separation between 
special education and curriculum staff: "sharing strategies, supporting each other talking about at-risk kids, talking about special needs." They also pushed frank discussion about teaching strategies and about expectations for aboriginal students' learning.

There was a lot more self-direction in the PLCs coming from teachers. It was more "Let's make sure we're focused and make sure we're doing something and our school energies are all being harnessed and directed in unison rather than us all paddling our own little canoes in different directions.

As teachers reflected on their students' performance data, collaborated, and discussed students' needs, the task of improving students' writing no longer mainly meant reviewing student performance on practice prompts or drills related to the high stakes standardized tests. Rather, as the PLC process "unfolded, we began to see more and more connection between early language development as oral language development [and] reading development, writing development, and overall literacy development." Staff became increasingly aware that many low-SES aboriginal students were entering school with very little existing language capacity whatsoever. During walkthroughs, staff presented early childhood classrooms where groups of students were using a variety of tools to build literacy skills (e.g. computers, board games, and manipulatives). Younger students now had their needs brought to the fore, and teachers began to see the connection to measured literacy performance in later grades.

PLCs could sometimes become quite confrontational, but mainly in a productive way. The district's data administrator described how it was:

Very confrontational for one teacher - not in a negative way, but they definitely felt that they needed to be able to defend the way that they wanted to mark and grade student work. And she walked away from the table understanding that she wasn't using a criterionbased assessment even though she had developed a rubric but [the grade was] based on the effort that they were working on. That was her peers at the table. She didn't go away upset. She went away saying, "I need to rethink this".

Facilitating the challenging work that enabled teachers to have productive and frank conversations took time. In the words of one teacher:

Pushing people outside of their comfort zone, as difficult as it is, it truly is successful because in time we were able to see changes in the content of discussion and the quality of the discussions that were happening around the table, but it took a lot of time.

Teachers said they were more frequently "listening to colleagues and watching what they're doing," and described how they were "more willing" to try colleagues' ideas since they had built "relationships." One said, "if we're going to be an effective school we need those relationships."

You would think that all this would make the superintendent and his staff selfcongratulatory about their success. There were definitely pressures in bringing about changes through "frank" conversations, and these were by no means always seen as positive and productive. The special education coordinator for the district talked about this tension: 
“Teachers definitely are feeling that they're under more scrutiny, more pressure from senior administration. Principals regularly are in classrooms. They're doing walkthroughs. They're looking for specific things. They want to see evidence that guided reading is happening. They want to see evidence of all of the initiatives that the board is working on. There is a lot of pressure on teachers to make changes and they certainly are feeling that pressure".

When this superintendent met with the research team and all his fellow district superintendents from elsewhere, he spoke movingly about how valuable the case study reports had been to him and his district. "I thought I was having challenging conversations with my staff", he said, to open up practice and raise expectations. "But since I read this report", he continued, "I realize that what I intended to be challenging conversations have sometimes been experienced as oppressive conversations". That is just the perception of some of my staff", he went on, "but perception is reality and I have to learn from this and take it very seriously".

Courageous leaders of PLCs are not bullying and self-congratulatory. They nudge, but they don't shove. They are humble and self-reflective. Commenting on the inherent difficulty of leading an effective PLC, Dave looked to his own practice. "To this day, even as a superintendent, I don't think I could hold (run) a perfect, effective PLC (discussion)", he said.

There are some powerful concluding lessons from this example about PLCs, their nature and their momentum. They have a back and forth feel between the relative contribution of pressure and support, push and pull, focus and flexibility, relationships and results. In this district,

- Teachers are pulled into something they find energizing, that they are given time for, and that respects their collective (not individual) professional autonomy and discretion; yet they are also pushed to review or revise what has been more or less effective for them, and to acquire practices from other colleagues who may be doing some things better.

- PLCs have a clear focus, but this is collectively and flexibly determined by the community - not administratively imposed on everyone, in a standardized way, from outside.

- There is a sense of urgency about challenging teachers' practice, yet also a patient realization that the essential trust and relationships that underpin PLCs can only develop over time.

- The superintendent is firm and persistent enough to challenge his teachers and leaders with frankness, yet humble and open enough to know when he has to pull back because he has gone too far. 


\section{Conclusion}

A professional culture, we have seen, connects the way people perform their work, to the people they are, the purposes they pursue, the colleagues they have, and how they do or don't improve. In the old days, and still too much today, the professional culture of teaching was one of individual classroom autonomy, unquestioned experience and unassailable knowledge and expertise. Nowadays, professional cultures are more and more collaborative. Teachers may still actually teach alone for much of the time, but the power of the group, and all the group's insight, knowledge, experience and support, is always with them. The best groups are places where teachers share collective responsibility for all their students - with teachers in other subjects and grades, and with teaching assistants as well. They are places where teachers constantly inquire into learning and problems together, drawing on their different experiences of particular children or strategies, and on what the evidence they can collect is telling them - about the best way to approach a child, a difficult curriculum concept, an unfamiliar innovation, or a group of learners who are falling behind, together. And they are places where teachers don't just endure but actively enjoy challenging and being challenged by their colleagues and their administrators when results are disappointing, levels of commitment and standards of professionalism start to wane, old habits are not supported by the evidence of what's effective, change efforts seem headed in the wrong direction, behaviour is personally inconsiderate, or there are just better ideas around that need to be embraced in order to move things ahead.

Professional learning communities need an architecture or design if they are going to be productive. They have to be organized and arranged. As in Finland, where teachers spend less of their time in classrooms with their students than any other developed country, time allocations in the school day have to honor teachers' need to have time outside of the classroom together to inquire into their practice and how to improve it together (Sahlberg 2011). Team meetings need a commonly agreed purpose and agenda. Staff meetings need to look more like high quality professional learning than places to deliver announcements. Teachers have to be drawn or pulled into these communities, as well as driven or pushed by them. In the very best cases, teaching itself is often collaborative. It's the joint work that Judith Warren Little (1990) recommended - with integrated projects moving across grade levels, middle school teachers working in teams who share and often teach large groups of students together, and special educational resource teachers working alongside grade level teachers in the regular classroom setting, for example. In all these cases, professional collaboration is structured, expected, simply the way of working that teaching now has to be. 
The days when individual teachers could just do anything they liked, good or bad, right or wrong, are numbered, and in many places, now obsolete. Teaching is a profession with shared purposes, collective responsibility and mutual learning.

But the new expectation that professional cultures have to be ones of collective autonomy, transparency and responsibility, that have to be deliberately arranged and structured around these principles, should not be a license for administrative bullying and abuse or enforced contrivance either. When push comes to shove, as it were, professional learning communities are not and should not be professional data communities or professional test score communities. They are not and should not be places for administrators to shove questionable district agendas on to teachers who are gathered together after busy days in class to pore over spreadsheets simply to come up with quick interventions that will raise test scores in a few weeks or less. They are not and should not be places where overloaded literacy coaches convene hurried meetings with harried teachers who scarcely have time to refocus from the preceding class, before they have to rush off to the next one. Nor are they or should they be places where principals and superintendents convert challenging conversations into hectoring harangues, and where all the challenges come from above, with no comebacks or reciprocal challenges allowed from teachers themselves.

The core principles of professional learning communities that are consistent with their origins are about teachers developing their commitments and capabilities, pushing and pulling but never shoving their peers, and exercising collective responsibility together for the greater good of students that transcends them all. Professional learning communities and collective responsibility will not look identical in all cultures and contexts. In Finland, they look like teachers being given a problem, then quietly solving it together. In Singapore, they are urgent, energetic and always involves food, in a highpowered culture where, as one Singaporean educator put it, "we eat and we run. We eat and we run!" (Hargreaves and Shirley 2012). But in all cases, wherever resources allow, professional autonomy can no longer be reducible to individual classroom autonomy, collective responsibility should be a key goal in building professional learning communities, and while the process for creating this collaboration will often require the nudges of deliberate arrangements to enhance learning, it should never extend to the forceful shoving and bullying of forced implementation that is the antithesis of the very thing it is claiming to create. 


\section{References}

Bird SM, Cox D, Farewell VT, Goldstein H, Holt T, Smith PC (2005) Performance indicators: good, bad, and ugly. J Roy Stat Soc A Sta, Series A, 168, Part 1, 1-27

Datnow A (2011) Collaboration and contrived collegiality: revisiting Hargreaves in an age of accountability. J Educ Change 12(2):147-158

Datnow A, Park V (2012) Structures and cultures of collaboration: the use of data among teachers working together. Paper presentation at the annual meeting of the American Educational Research Association, San Francisco, 17 April 2012

Davis B, Sumara D (2009) Using complexity science to study the impact of AISI on cultures of education' in Alberta. In: Hargreaves A, Crocker R, Davis B, McEwen L, Sahlberg P, Shirley

D, Sumara D. with Hughes M (eds.) The learning mosaic: a multiple perspectives review of the Alberta Initiative for School Improvement (AISI), pp 34-50. http://education.alberta.ca/ media/1133263/the\%20learning\%20mosaic. pdf

Dufour R (2011) Work together: but only if you want to. Phi Delta Kappan 92(5):57-61

Finnigan K, Daly AJ, Che J Mind the gap: learning, trust, and relationships in an underperforming urban system. Am J Educ (in press)

Fullan M (2011) Choosing the wrong drivers for whole system reform, vol 204, Seminar series. Centre for Strategic Education, East Melbourne

Hargreaves A (1994) Changing teachers, changing times: teachers' work and culture in the postmodern age. Teachers College Press, New York

Hargreaves A, Braun H (2012) Leading for all: final report of the review of the development of essential for some, good for all - Ontario's strategy for special education reform devised by the Council of Directors of Education. Council of Directors of Education, Toronto
Hargreaves A, Dawe R (1990) Paths of professional development: contrived collegiality, collaborative culture, and the case of peer coaching. Teach Teach Educ 6(3):227-241

Hargreaves A, Fullan M (2012) Professional capital: transforming teaching in every school. Teachers College Press, New York

Hargreaves A, Harris A (2011) Performancebeyond expectations. The study is documented in a report for the National College for School Leadership in the UK. http://www.national college.org.uk/index/leadershiplibrary/ leadingschools/school-improvement/ international-perspectiveson-developing -high-quality-leadership/performancebeyond-expectations.htm

Hargreaves A, Shirley D (2012) The Global fourth way: architectures of educational excellence. Corwin Press, Thousand Oaks

Hargreaves A, Skelton J (2011) Politics and systems of coaching and mentoring. In: Fletcher $S$, Mullen C (eds) The Sage handbook of mentoring and coaching in education. Sage, Los Angeles

Hargreaves A, Halász G, Pont B (2008) The Finnish approach to system leadership. In: Pont B, Nusche D, Hopkins D (eds) Improving school leadership, Vol 2: Case studies on system leadership. OECD, Paris, pp 69-109

Hord SM (1997) Professional learning communities: communities of continuous inquiry and improvement. Southwest Education Development Laboratory, Texas

Klette K (1997) Teacher individuality, teacher collaboration and repertoire building: some principal dilemmas. Teach Teach 3(2):243-256

Little JW (1990) The persistence of privacy: autonomy and initiative in teachers' professional relations. Teach Coll Rec 91(4):509-536

McLaughlin M, Talbert J (2001) Professional communities and the work of high school teaching. University of Chicago Press, Chicago 
Mourshed M, Chinezi C, Barber M (2010) How the world's most improved school systems keep getting better. McKinsey \& Company, London.http://mckinseyonsociety.com/how -the-worldsmost-improved-school-systems -keep-getting-better/

Naylor C (2005) A teacher union's collaborative research agenda and strategies: one way forward for Canadian teacher unions in supporting teachers' professional development. British Columbia Teachers Federation, Vancouver

Newmann FM, Wehlage G (1995) Successful school restructuring. Center on organization and restructuring of schools, Madison, WI. http://www.wcer.wisc.edu/archive/cors/ Successful_School_Restruct.html

Nias J (1989) Primary teachers talking: a study of teaching as work. Routledge, London

Rosenholtz SJ (1991) Teacher's workplace: teachers' workplace: the social organization of schools. Longman Group, Harlow
Sahlberg P (2011) Finnish lessons: what can the world learn from educational change in Finland? Teachers College Press, New York

Schwartz B (2005) The paradox of choice: why more is less. Harper, New York

Thaler RH, Sunstein CR (2008) Nudge: improving decisions about health, wealth, and happiness. Yale University Press, New Haven

Waller W (1932) The sociology of teaching. Wiley Press, Hoboken

Wood D (2007) Teachers' learning communities: catalyst for change or a new infrastructure for the status quo? Teach Coll Rec 109(3):699-739

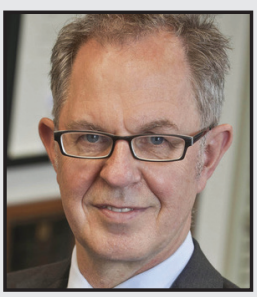

Andy Hargreaves is the Thomas More Brennan Chair in the Lynch School of Education at Boston College. Before that, he was the co-founder and co-Director of the International Centre for Educational Change at the Ontario Institute for Studies in Education. Andy has authored or edited over 30 books, several of which have achieved outstanding writing awards from the American Educational Research Association, the American Libraries Association, and the American Association of Colleges for Teacher Education. One of these, Professional Capital: Transforming Teaching in Every School (with Michael Fullan, 2012) has received three prizes including the prestigious Grawemeyer Award in Education for 2015. 